\title{
SPATIAL ANALYSIS OF URBAN NETWORK OF WROCŁAW
}

\author{
AHMED A. H. SAEID, ROBERT MASZTALSKI \\ Faculty of Architecture, Wrocław University of Technology \\ Bolesława Prusa 53/55, 50-317 Wrocław, Poland \\ e-mail: aasaeid@gmail.com robert.masztalski@pwr.wroc.pl
}

\begin{abstract}
The paper aims to understand the morphological transformation of the urban network of Wrockaw caused by the rapid development and urban growth impacts. In an attempt to investigate the reason for morphological transformation of Wrockaw urban network, the study focuses on the analysis of their spatial transformation through the comparative syntactic analysis during the historic process of growth of Wrocław. The spatial analysis based on 'Space Syntax' theories and techniques.
\end{abstract}

Key words: spatial morphology, urban network, urban growth, Space Syntax Theory, Wrocław.

\section{INTRODUCTION}

Throughout the European regions, wide developments and new challenges happened in the spatial structure of urban networks of cities, due to economic growth, social-cultural changes and political transformations have had a significant impact on the spatial planning of European cities.

These effects have been taking a place within the urban network of a city or a region at global and local level.

The paper dealt the spatial structure of urban network of Wrocław, the capital city of Lower Silesia Region, in different periods as a case study.

The objective of this paper is to understand the morphological transformation of the urban network of Wrocław city caused by the rapid development and urban growth impacts. The paper aimed to analyze the spatial structure of urban network of Wrocław through studying the syntactic parameters, configuration properties and structural properties. 
The study used space syntax methodology, which is a method to investigate and understand the spatial structure of settlements, and to give quantity descriptions of urban space in a comparative way. Space syntax, is a research program that developed by Hillier and Hanson at the Unit for Architectural Studies, University College London, is a technique that can be used for morphological analyses of architecture and spatial planning. The aim of the technique is to describe different aspects of relationships between the morphological structure of human-made environments and social structures or events.

The analysis of case study was done by representing the axial maps for the cartographical maps of Wrocław in different study periods (1804-2008). These axial maps have been processed by the space syntax measures to reveal the properties of spatial structure of the urban network. Later on, these maps will be compared to understand the morphological transformation of the urban network that caused by the urban growth. The study will attempt to identify whether the urban development and their further transformations in the pattern of urban network follow any spatial logic.

\section{CASE STUDY: WROCŁAW}

Wrockaw is the capital of the province of Lower Silesia and Poland's fourth largest metropolis. Ranked as the 33rd largest city in the European Union, Wrocław is a strong economic, academic and cultural centre. Wrocław is located in the south-western part of Poland, the region of Lower Silesia shares borders with both the Czech Republic and Germany, with total area $293 \mathrm{~km}^{2}$. The total population of Wrocław is 635,200 inhabitants and the density is 2.36 inhabitant $/ \mathrm{m}^{2}$, according to 2006 statistics (Statistical Yearbook of Wrocław, <http://www.Wrocław.pl>).

Within Lower Silesia, which has the country's densest transport infrastructure and good cross-border co-operation with its German and Czech neighbours, Wrockaw is an important transport hub at the intersection of three international routes with two major railway stations, two river ports and an international airport. The city has the largest number of bridges in the world after Venice, Amsterdam and St. Petersburg. It is nearly equidistant from Berlin, Prague and Warsaw (OECD 2008).

According to its favourable geographical position at a commercial crossroad as well as to a recent wave of foreign investment, Wrocław has become a frontrunner of economic development. Its location on the A4 motorway, which links Wrocław with Germany and two other major Polish metropolitan areas (Katowice and Cracow) has been crucial. Wrockaw has attracted a number of leading multinational companies. Wrocław's agglomeration ranks second after Warsaw in terms of size of investments. It is also the second larger centre of financial services in Poland (OECD 2008), (Figure 1). 


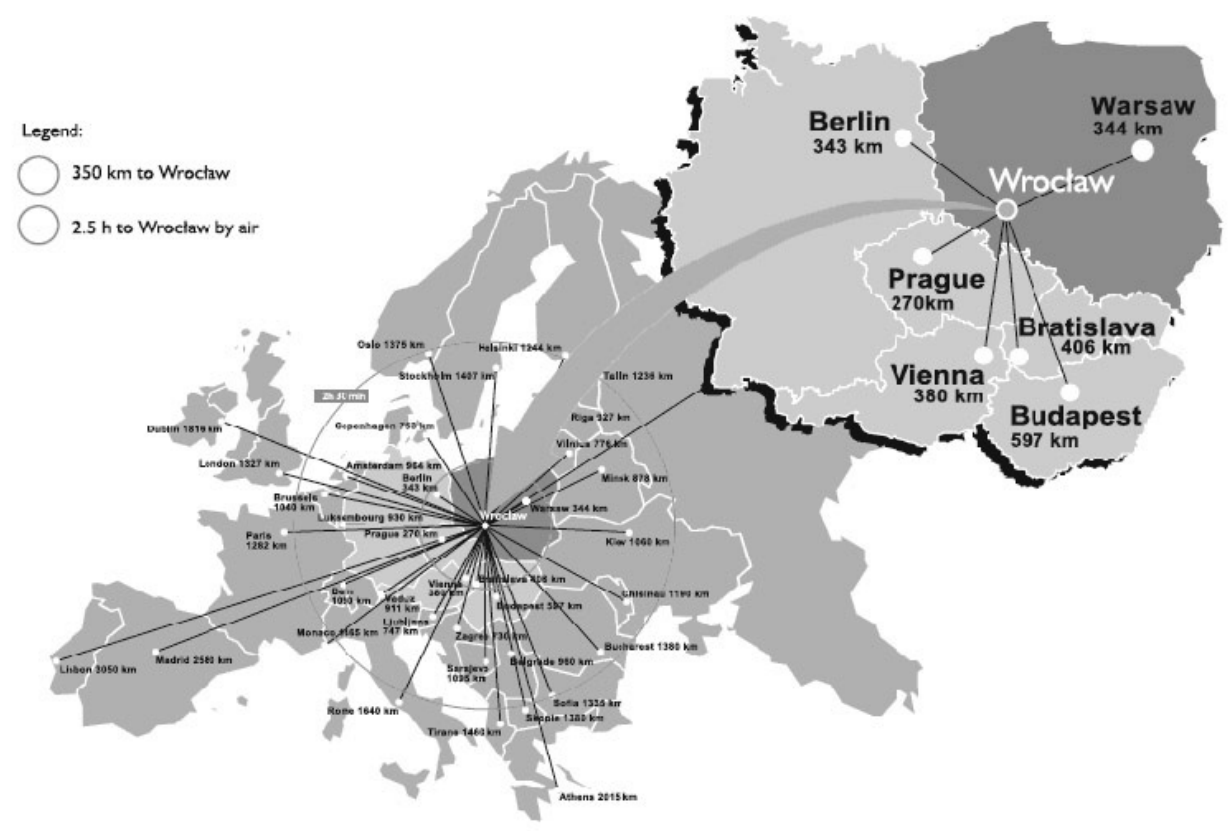

Figure 1. The Strategic location of Wrocław within Poland and Europe Source: ARAW (2009).

\section{THE METHODOLOGY: SPACE SYNTAX THEORY}

It is possible to find various methods and approaches created for reading and analyzing the space in the architecture literature. One of the important theories in recent years that is also used as a method in this study related to analyzing morphology of the city, is space syntax (Hillier and Hanson 1984).

Space syntax is a research program developed by Hillier and Hanson at the Unit for Architectural Studies, University College London (Hillier and Hanson 1984). It is a technique that can be used for morphological analyses of buildings, architectural plans and urban plans. The aim of this technique is to describe different aspects of relationships between the morphological structure of human-made environments and social structures or events.

Hillier states that the city is composed of economic processes, social relations, psychological expressions and cultural environments rather than of solely formed physical environments. The urban network of a city can be analyzed in different ways with the help of these factors. These features make up the foundations of different physical structures seen in different environments and cities, which form them and give them a meaning. In order to analyze the urban network by using space syntax theory, it is necessary to understand the basic concepts of this theory-convex space and axial space. These concepts depend upon the main principles that try to represent the difference of open versus closed spaces and large versus small spaces. However, 
due to understanding and implementation of these principles and concepts, quantitative measures have been derived to interpret the syntactic parameters, configuration properties and structural properties of urban network.

\section{SPACE SYNTAX PRINCIPLES}

Space syntax is based on two important principles to understand and represent the spatial system of urban environment.

\section{OPEN VERSUS CLOSED SPACES}

An urban environment consist of two parts: one termed as closed spaces and another termed as open space. The open versus closed spaces distinction is generated by the existence of boundaries between the streets and the built environment, i.e. open and closed spaces are interdependent as they share a common physical boundary. These theories provide support for spatial configuration modelling of an urban system.

The distinction between open and closed spaces is based on possible movements within these structures: an open space allows a human being to have free movement from any point to any other point in the open space, while a displacement within a close space is, by definition, restricted to the boundaries of this closed space. In the context of a city, urban blocks or plots are considered as closed spaces, while streets and squares as parts of the open space. The human perception and understanding of the city or the formation of its mental representation is realized through navigation, exploration of landmarks and places, alternatively by reading city maps (Jiang and Claramunt 1999), (Figure 2).

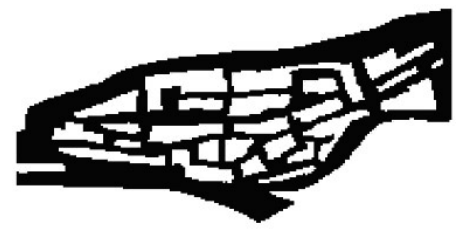

Figure 2. The open space structure of Gassin in the south of France Source: Hillier, B. and Hanson, J. (1984).

\section{LARGE-SCALE VERSUS SMALL-SCALE SPACES}

The distinction between large-scale and small-scale spaces is a fundamental assumption for the space syntax application. From the spatial perception point of view, a large-scale space is beyond human body perception and cannot be perceived from a single vantage point; while a small-scale space is presumably larger than human body, but can be perceived from a single vantage point. In the large-scale environments human being updates his/her perception of small-scale space whilst moving along in the large-scale space. In other words, a perception of a large-scale space is generated from perception in small-scale spaces.

Small-scale spaces are continuous and interconnected. When we are walking along a street, we perceive our surrounding environment as a small-scale space. Small-scale 
spaces are interconnected in the sense that a large-scale space consists of an infinite, but countable, number of small-scale spaces.

Small-scale spaces are interconnected to form the so called open space. In order to derive an analytical tool based on a small-scale space perspective, there is a need for, first, a representation of a large-scale space as a number of small-scale spaces and, secondly, a definition of a link between these individual small-scale spaces to form a graph of connectivity (Jiang and Klarqvist 2000).

\section{SPACE SYNTAX CONCEPTS}

There are two important concepts in space syntax analysis, which are represented in convex space and axial space.

\section{CONVEX SPACE}

Convex space is a two-dimensional space in which all points are directly accessible and visible from all points. The convex space is represented by a convex polygon in $2 \mathrm{D}$ maps. A polygon is said to be convex if no line drawn between any two points in that polygon goes outside the polygon (Hillier et al. 1987). The convex space defined in the spatial system by dividing the open space in the least set of broadest spaces that cover the whole open space, (Figure 3).

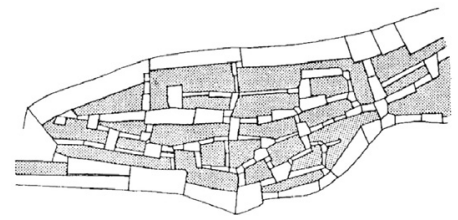

Figure 3. Convex map of Gassin in the south of France Source: Hillier, B. and Hanson, J. (1984).

\section{AXIAL SPACE}

Axial space is a one-dimensional space, represented by axial line drawn between two points and perceived as one directly accessible and visible pass through at least some points in other convex spaces (Hillier et al. 1987).

The axial space is defined in the spatial system by drawing the least number of longest straight axial lines within the whole open space. So that every convex space will be crossed by at least one of axial space, (Figure 4).

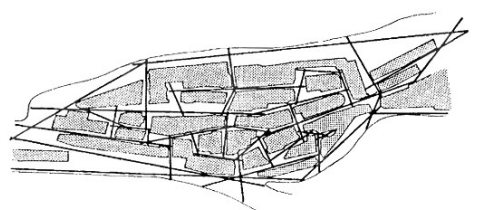

Figure 4. Axial map of Gassin in the south of France Source: Hillier, B. and Hanson, J. (1984). 


\section{CONVEXITY AND AXIALITY}

Convexity or axiality can be used to represent the whole space system. A convex map will be a set of fattest and fewest spaces that cover the system, while an axial map will be the set of longest and fewest straight lines that go through all convex spaces and make all axial links. Every point in the system has both a one- and two-dimensional form. This means that every point already contains both a local and a global form. A convex space is the most localized space because it extends only so far as is consistent with every point being visible and directly accessible to every other point, while an axial line is the most globalized since it extends as long as there is at least one point visible and directly accessible.

A convex space describes where you are in the system, whereas axial lines give information about where you might be going. Axiality adds relationships to those created locally, and inserts a space into the overall structure of spatial order and movement within a town. Axiality seems closely associated with patterns of movement. Convexity, on the other hand, seems less associated with movement than with the co-presence of those who are already there (Hillier et al. 1987).

\section{SYNTACTIC MEASURES OF URBAN NETWORK}

Basically, there are two types of syntactic measures in space syntax; first global measures such as mean depth, global integration and choice value, secondly local measures such as local integration, connectivity and control value.

\section{MEAN DEPTH}

The mean depth (Di) is simply the topological distance to reach another axial line in the urban system, dij. Since axial lines are straight, in practice this corresponds to the number of turns an individual would have to make. It follows that the depth from one axial line directly accessible to another axial line is 1 . The total depth is the sum of all topological distances between an axial line and all other axial lines (L) in the urban system and is defined as

$$
D_{i}=\sum_{j=1, j \neq i}^{L-1} d_{i j}
$$

The mean depth $(\bar{D} i)$ indicates how close on average an axial line (L) is to all other axial lines in the urban system and is defined as (Hillier and Hanson 1984).

$$
\bar{D}_{i}=\frac{D_{i}}{L-1}
$$

Relative asymmetry is defined as the ratio of the difference between the actual mean depth of a line and the minimum mean depth $(\bar{D} i-1)$ to the difference between the maximum mean depth and the minimum mean depth $\left(\frac{\boldsymbol{L}}{2}-\mathbf{1}\right)$. Thus, 


$$
R A_{i}=\frac{2(\bar{D}-1)}{L-2}
$$

This transformation standardizes the mean depth to a value between zero and one. Figure 5. depicts the construction of $R A_{i}$ (Hillier and Hanson 1984), (Teklenburg et al., 1993).

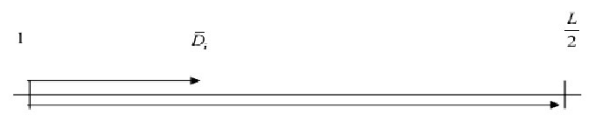

Figure 5. Construction of relative asymmetry Source: Teklenburg, J. A. F. et al., (1993).

Thus, the real relative asymmetry $\left(R R A_{i}\right)$ is

$$
R R A_{i}=\frac{R A_{i}}{R A^{D}}
$$

where $R A^{D}$ is the relative asymmetry of the root of the diamond-shaped system.

\section{GLOBAL INTEGRATION}

The global integration value is defined as the inverse of, and it is expressed for a space by a value that indicates the degree to which a space is integrated from a system as whole.

$$
\text { Integration Value }=\frac{1}{R R A_{i}}
$$

\section{GLOBAL CHOICE}

The choice value is defined as a strong choice value of space when many of shortest paths, connecting all spaces to all spaces of urban system, passes through it. Regardless of depth, the urban system is represented as a tree of connectivity graph, which has k spaces (axial lines) and k-1 links (intersections of axial lines), will has only one route from any space to any other. Alternative routes will therefore show themselves as rings in the graph. Spaces can be distinguished from each other according to whether or not they lay on rings, how many rings they lie on, and which rings they lie on (Hillier and Hanson 1984).

\section{LOCAL INTEGRATION}

The local integration value can be described from integration value but it is expressed for a space by a value that indicates the degree to which a space is integrated from a partial system as a few steps away (Hillier and Hanson 1984).

\section{CONNECTIVITY}

Connectivity is defined as the number of axial lines directly linked to each individual axial line in connectivity graph, 


$$
C_{i}=k
$$

where $\mathrm{k}$ is the number of axial lines directly linked (Jiang \& Klarqvist 2000).

The connectivity graph is dual graph of an axial map, and it is derived by representing axial lines and line intersections from an axial map as nodes and links, respectively, as shown in Figure 6, (Jiang and Claramunt 2002).
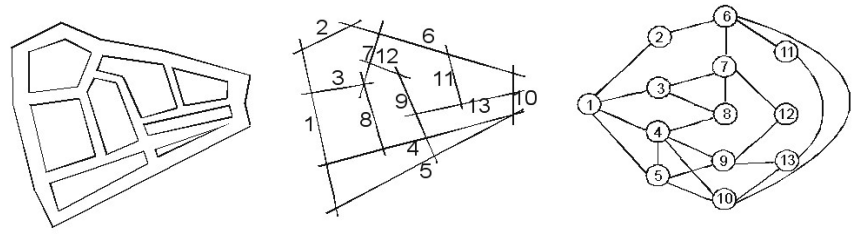

Figure 6. The connectivity graph of axial map

Source: Jiang, B. and Claramunt, C. (2002).

\section{CONTROL VALUE}

Control value is defined as a parameter which expresses the degree of choice each axial line represents for axial lines directly linked to it. The control value $\left(c t r l_{i}\right)$ of an axial line (i) is given by the sum of the inverse connectivity values of the jth directly linked axial lines (k) (Jiang \& Klarqvist 2000), as the following equation:

$$
\operatorname{ctrl}_{i}=\sum_{j=1}^{k} \frac{1}{c_{j}}
$$

\section{CONFIGURATION PROPERTIES OF URBAN NETWORK}

The configuration properties of urban network of a settlement can be defined by the correlations between the global and local measures. These correlations describe the part-whole relationship within the spatial configuration of urban network. There are two kinds of configuration properties, as follows intelligibility and synergy.

\section{INTELLIGIBILITY}

Intelligibility is defined as the degree to which what can be seen and experienced locally in the system allows the large-scale system to be learnt without conscious effort (Hillier 1996). The intelligibility value is calculated by the degree of linear correlation between connectivity and global integration value (Hillier and Hanson 1994).

\section{SYNERGY}

Synergy, calculated by the degree of linear correlation between local integration and global integration, is used to lessen the influence of system size (Hillier et al. 1993).

\section{STRUCTURAL PROPERTIES OF URBAN NETWORK}

The structural properties of urban network of a settlement can be measured by the core. The core is the most important deep structure of the urban network and 
it will vary from one settlement to another. The core of a settlement is $5 \%, 10 \%$ or $25 \%$ depending on what is to be shown, of high values of the measure.

The core takes a form called a deformed wheel which is consist of, a semi grid, or "hub" of lines in the interior of the settlement is linked by lines, or "spokes", in several directions to peripheral, or "rim" lines. The shape of the core gives major clues to type of the culture that created the spatial pattern (socio-spatial genotype).

In space syntax, the structural properties of urban network were represented in the three most important cores as follows, the global integration core, the global choice core and the local integration core.

\section{THE GLOBAL INTEGRATION CORE}

The global integration core is represented by $10 \%$ (or $5 \%$ or $25 \%$ ) of the highest values from the total values of global integration of axial lines for that axial map of a settlement (Hillier and Hanson 1994). The pattern of main centre of a settlement can be shaped by the global integration core which it is described as a global closeness centrality measure of the urban network.

\section{THE GLOBAL CHOICE CORE}

The global choice core is represented by $10 \%$ (or $5 \%$ or $25 \%$ ) of the highest values from the total values of global choice of axial lines for that axial map of a settlement (Peponis et al. 1989). The pattern of global accessibility of a settlement can be shaped by the global choice core which it is described as a global betweenness centrality measure of the urban network. This means that there are a few streets or street segments, which are not only the most accessible locations but also important constituents of the shortest topological routes within the settlement (Wang 2009).

\section{THE LOCAL INTEGRATION CORE}

The local integration core is represented by $10 \%$ (or $5 \%$ or $25 \%$ ) of the highest values from the total values of local integration of axial lines for that axial map of a settlement (Hillier and Hanson 1984). The pattern of sub centres and the pattern of local accessibility of a settlement can be shaped by the local integration core which it is described as a local closeness centrality measure of the urban network.

\section{SPATIAL ANALYSIS OF URBAN NETWORK OF WROCŁAW}

Spatially, the urban network of Wrocław was analyzed by using the space syntax methodology. The analysis of Wrocław urban network was done in three kinds of measurement; the syntactic measures, the configuration properties and structural properties. In this paper, the urban network of Wrocław was developed based on the cartography maps of Wrocław in different study periods, as follows 1807, 1847, 1873, 1891, 1912, 1928, 1938, 1948, 1967, 1977, 1988, 1998 and 2008. 
The axial maps of Wrocław urban network had drawn by AutoCAD software as a vector file (dxf.), and analyzed by space syntax software (MindWalk 1.0) (Figueiredo 2005), to calculate the syntactic parameters. The statistic software (Statistica 8.0) was used as a tool to correlate between the global and local syntactic parameters by the linear regression model to get the configuration properties values of Wrockaw urban networks.

\section{SYNTACTIC PARAMETERS OF URBAN NETWORK OF WROCŁAW}

The syntactic parameters of Wrocław urban network were calculated by two kinds of measures, the global syntactic measures are global integration, mean depth and global choice, and, the local syntactic measures are local integration and connectivity. Table 1 shows the averages of syntactic parameters of Wrocław urban network in different periods, from 1807 to 2008.

Table 1. Syntactic parameters of axial maps for urban network of Wrocław in different periods

\begin{tabular}{|c|c|c|c|c|c|c|}
\hline \multirow{2}{*}{$\begin{array}{l}\text { Syntactic } \\
\text { Measures } \\
\text { Year }\end{array}$} & \multirow{2}{*}{$\begin{array}{l}\text { No. of } \\
\text { Axial } \\
\text { Lines }\end{array}$} & \multicolumn{3}{|c|}{ Global Measures } & \multicolumn{2}{|c|}{ Local Measures } \\
\hline & & $\begin{array}{l}\text { Mean } \\
\text { Depth }\end{array}$ & $\begin{array}{c}\text { Global } \\
\text { Integration }\end{array}$ & $\begin{array}{l}\text { Global } \\
\text { Choice }\end{array}$ & $\begin{array}{c}\text { Local Integration } \\
\text { R3 }\end{array}$ & Connectivity \\
\hline 1807 & 204 & 4.3922 & 0.9527 & 0.0385 & 1.6763 & 3.5294 \\
\hline 1847 & 489 & 6.3333 & 0.7377 & 0.0233 & 1.6048 & 3.3742 \\
\hline 1873 & 626 & 6.4984 & 0.7581 & 0.0184 & 1.6536 & 3.4585 \\
\hline 1891 & 771 & 6.0595 & 0.8461 & 0.0138 & 1.7219 & 3.6248 \\
\hline 1912 & 1437 & 7.8881 & 0.7196 & 0.0094 & 1.7264 & 3.6038 \\
\hline 1928 & 2477 & 10.537 & 0.5534 & 0.0076 & 1.5842 & 3.3045 \\
\hline 1938 & 3730 & 13.230 & 0.4705 & 0.0062 & 1.5789 & 3.3135 \\
\hline 1948 & 4104 & 13.864 & 0.4562 & 0.0058 & 1.5856 & 3.3181 \\
\hline 1967 & 4773 & 14.799 & 0.4285 & 0.0054 & 1.5626 & 3.2624 \\
\hline 1977 & 5394 & 18.126 & 0.3741 & 0.0055 & 1.5109 & 3.1605 \\
\hline 1988 & 5990 & 18.776 & 0.3637 & 0.0051 & 1.5097 & 3.1755 \\
\hline 1998 & 7229 & 20.047 & 0.3491 & 0.0045 & 1.4989 & 3.1301 \\
\hline 2008 & 9922 & 20.390 & 0.3736 & 0.0032 & 1.4897 & 3.0764 \\
\hline
\end{tabular}

The global integration value was used to analyze the transformation of urban structure in Wrocław centre and the urban growth of urban network through different periods. As well as, the global integration was used to understand the global accessibility (as a pattern of urban movement) within the urban network. It helped to understand how changes in society implied affected urban configuration. Figure 7 shows the global integration within the axial maps of Wrocław urban network in different periods, which it is concentrated in the historical centre of Wrockaw with the dark colour to decrease gradually to the peripheral areas of the city with the light colour through all the periods. At the same time, the averages of global integration value have 


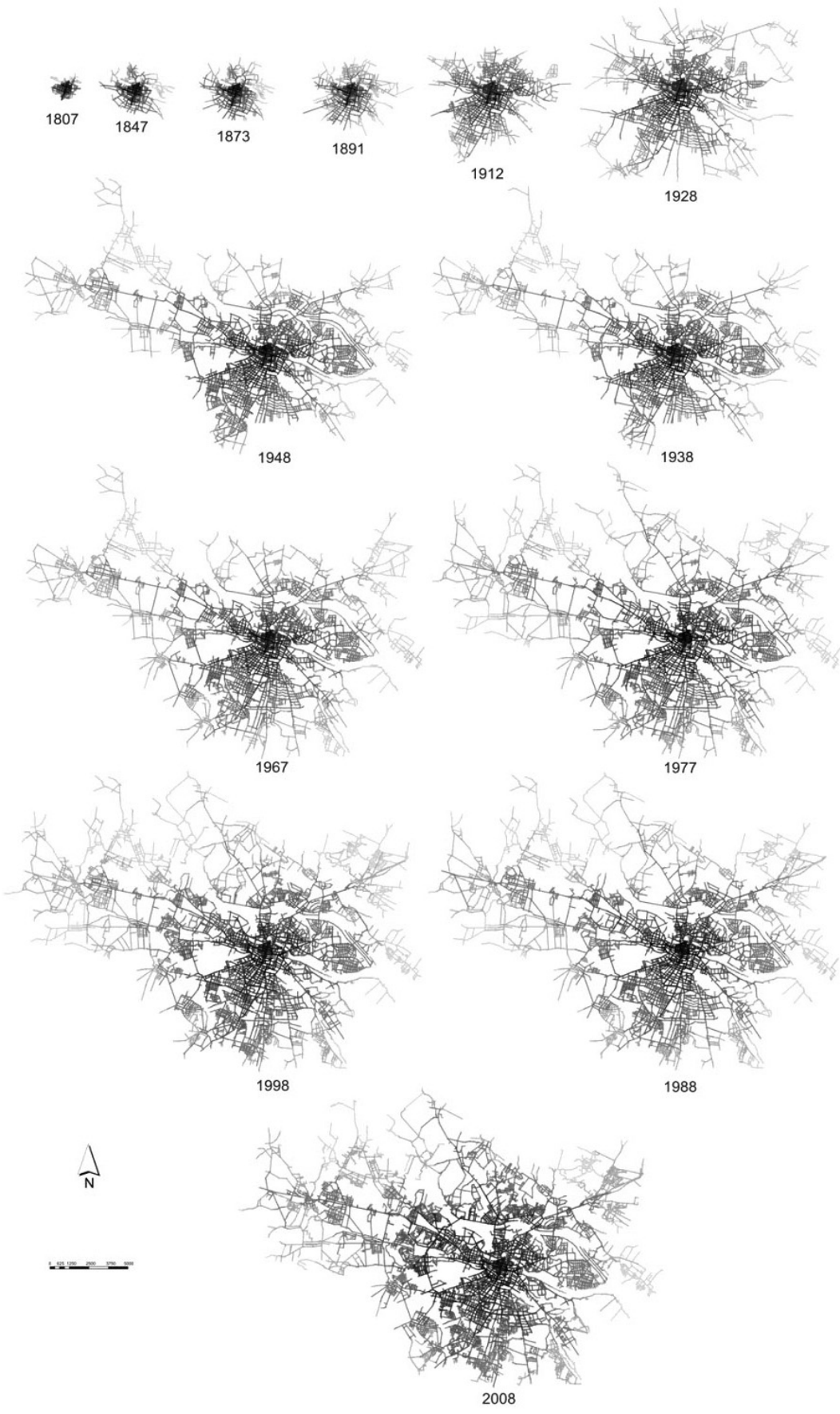

Figure 7. Global integration parameter of axial maps of Wrocław urban network in different periods Source: author. 
been decreased, as it is shown in Table 1, with the urban growth of Wroclaw urban network.

The mean depth value was used as a global parameter to represent the topological distances of the roads within the urban network. The Table 2 shows the averages of mean depth have been increased gradually with the urban growth of Wrocław urban network from 1804 to 2008. In other words, when the number of axial segments of Wrocław urban network increased, as a result, the topological distances would be increased then the number of more straight roads would be decreased. Therefore, the ability of urban structure would be less to generate the global accessibility of urban movement.

The global choice value was defined as a parameter of the shortest routes that connect the main centre with the edge of a city, at the same time; connect the local urban areas among them. The results show the averages of global choice of Wrockaw urban network has been decreased gradually with urban growth through all the study periods.

The local integration value was used as a dynamic local parameter to investigate the generation process and the transformation process of sub centres within the urban network as a result of the urban growth and urban expansion. Figure 8 shows the high values of local integration with dark colour that were concentrated in the historical city centre of Wrockaw through the period (1804-1912), while they were distributed gradually within the urban network through the period (1912-2008). Numerically, the Table 1 shows the averages of local integration values of Wrocław urban network had increased until year 1912 then have been decreased gradually with the urban growth of urban network.

Table 2. Configuration properties of axial maps for urban network of Wrocław in different periods

\begin{tabular}{|c|c|c|c|c|}
\hline \multirow{2}{*}{$\begin{array}{c}\text { Configuration } \\
\text { Properties }\end{array}$} & \multicolumn{2}{|c|}{ Intelligibility } & \multicolumn{2}{c|}{ Synergy } \\
\cline { 2 - 5 } & $\mathrm{R}^{2}$ & $\mathrm{y}$ & $\mathrm{R}^{2}$ & $\mathrm{y}$ \\
\hline 1807 & 0.282 & $3.759 \mathrm{x}$ & 0.699 & $1.756 \mathrm{x}$ \\
\hline 1847 & 0.180 & $4.554 \mathrm{x}$ & 0.552 & $2.161 \mathrm{x}$ \\
\hline 1873 & 0.174 & $4.565 \mathrm{x}$ & 0.536 & $2.172 \mathrm{x}$ \\
\hline 1891 & 0.175 & $4.316 \mathrm{x}$ & 0.536 & $2.036 \mathrm{x}$ \\
\hline 1912 & 0.139 & $5.016 \mathrm{x}$ & 0.431 & $2.390 \mathrm{x}$ \\
\hline 1928 & 0.151 & $5.953 \mathrm{x}$ & 0.452 & $2.847 \mathrm{x}$ \\
\hline 1938 & 0.122 & $6.992 \mathrm{x}$ & 0.403 & $3.332 \mathrm{x}$ \\
\hline 1948 & 0.108 & $7.208 \mathrm{x}$ & 0.309 & $3.443 \mathrm{x}$ \\
\hline 1967 & 0.093 & $7.522 \mathrm{x}$ & 0.312 & $3.603 \mathrm{x}$ \\
\hline 1977 & 0.080 & $8.343 \mathrm{x}$ & 0.259 & $3.991 \mathrm{x}$ \\
\hline 1988 & 0.093 & $8.650 \mathrm{x}$ & 0.246 & $4.105 \mathrm{x}$ \\
\hline 1998 & 0.084 & $8.879 \mathrm{x}$ & 0.215 & $4.242 \mathrm{x}$ \\
\hline 2008 & 0.067 & $8.175 \mathrm{x}$ & 0.181 & $3.952 \mathrm{x}$ \\
\hline
\end{tabular}

Source: author. 


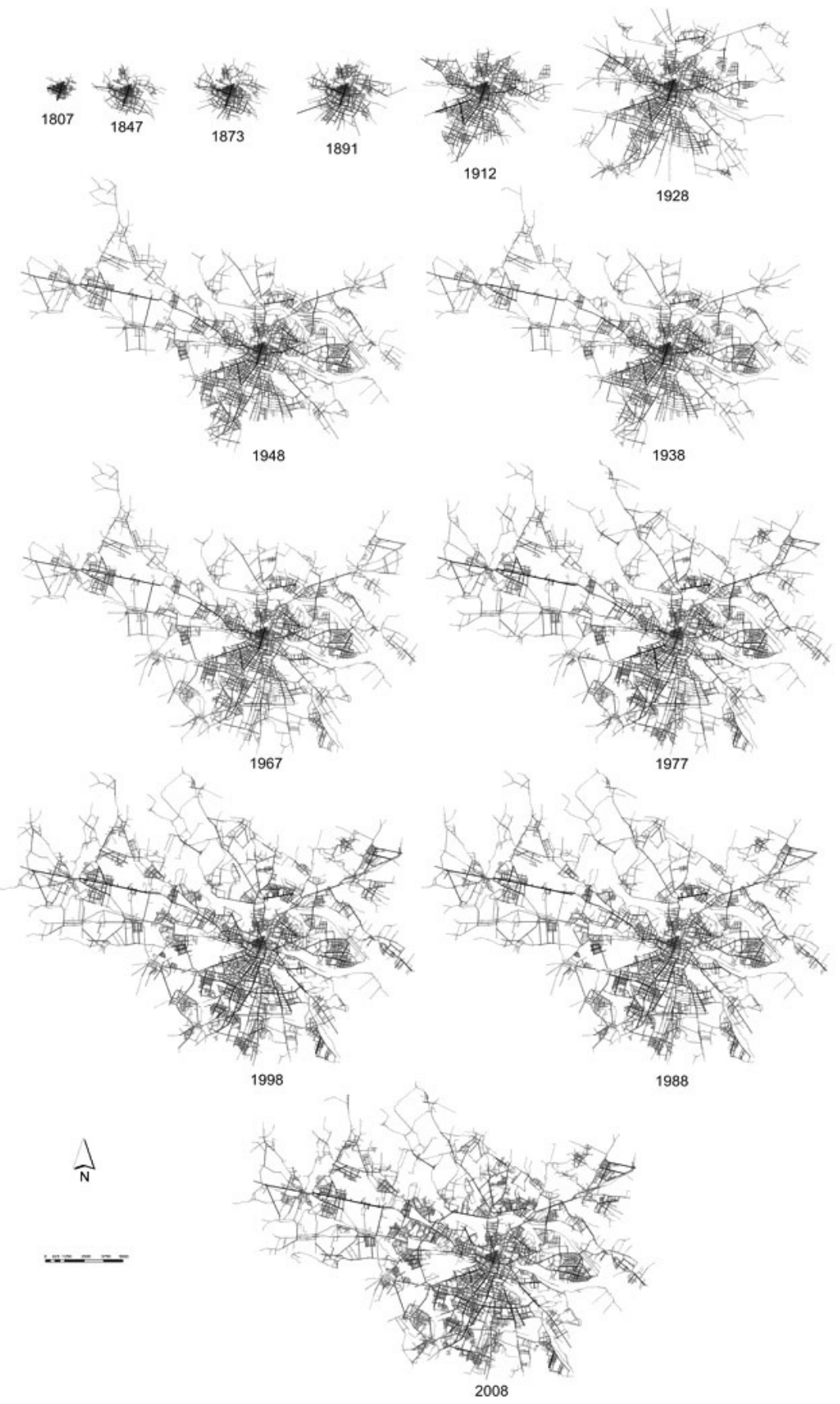

Figure 8. Local integration parameter of axial maps of Wrocław urban network in different periods

Source: author. 
The connectivity was defined as a static local parameter to account for all the direct connections each road has to other roads in the urban network. Table 1 shows the averages of connectivity values have been decreased with the urban growth of Wrocław urban network.

\section{CONFIGURATION PROPERTIES OF URBAN NETWORK OF WROCŁAW}

The configuration properties of Wrockaw urban network can be measured by intelligibility and synergy. The intelligibility was measured by the correlation between the connectivity and the global integration to give a clue of how the urban network is clear to its users. While the synergy (local area effect), was used to indicate the relationship between local parts and global parts. It was measured by the correlation between the local integration and global integration.

Figure 9 shows how the configuration properties (intelligibility and synergy) have been decreased with the urban growth of urban network of Wrocław through the different study periods.

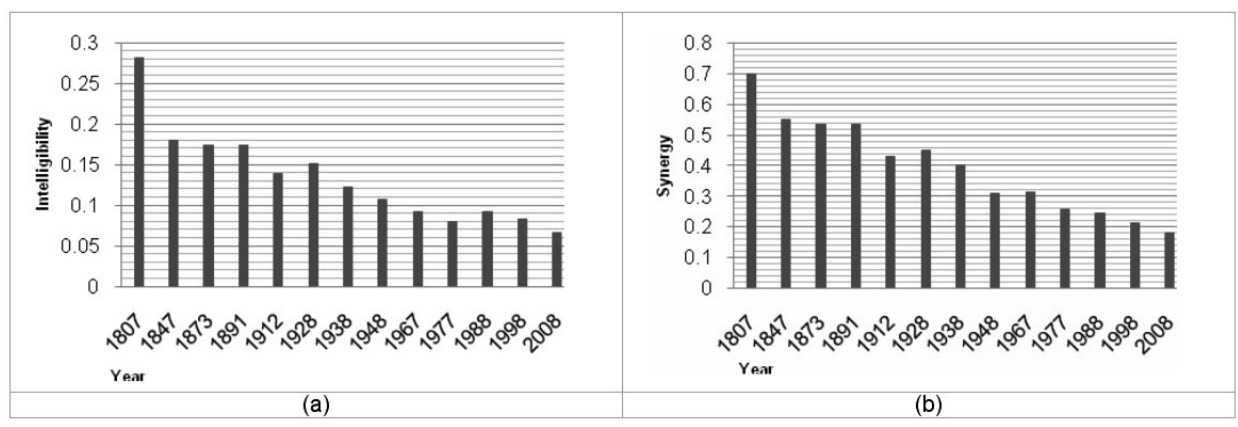

Figure 9. Configuration properties (a) the intelligibility and (b) the synergy of axial maps of Wrocław urban network in different periods

Source: author.

\section{STRUCTURAL PROPERTIES OF URBAN NETWORK OF WROCŁAW}

In this paper, the structural properties of Wrocław urban network were represented in three kinds of cores. They were global integration core, global choice core and local integration core. Each core consists of $10 \%$ of the highest values of the structural property.

The global integration core of Wroclaw was appeared to have had a dynamic structure that has been transformed with time; although it shows a continual expansion and shift in succeeding phase of urban growth, as it is shown in Figure 10. The global integration core of Wrocław was formed as a semi grid or hub lines centralized in the historical city centre from 1804 to 1873 . The centralized core was started to grow in 1891 by spokes in the southern direction until 1928 to include big part from the southern surrounded area of historical city centre. From 1938 to 1998 the core was expanded in all the direction but still has been kept the biggest part in the southern surrounded area. In 2008, the global integration core of Wroclaw was formed as a deformed wheel by connecting the spokes lines in the northern, western and southern 


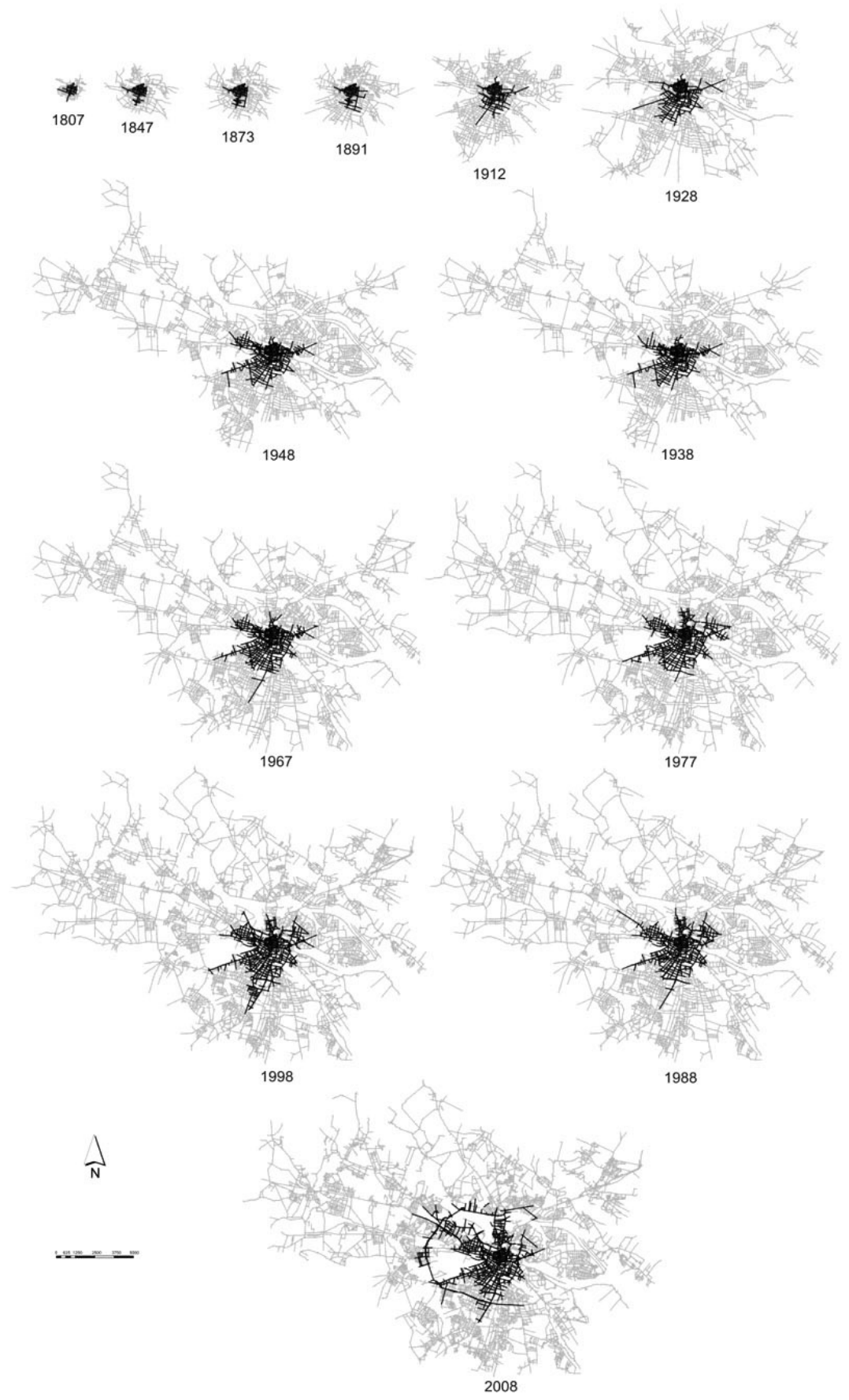

Figure 10. Global integration core of axial maps of Wrocław urbann Network in different periods Source: author. 


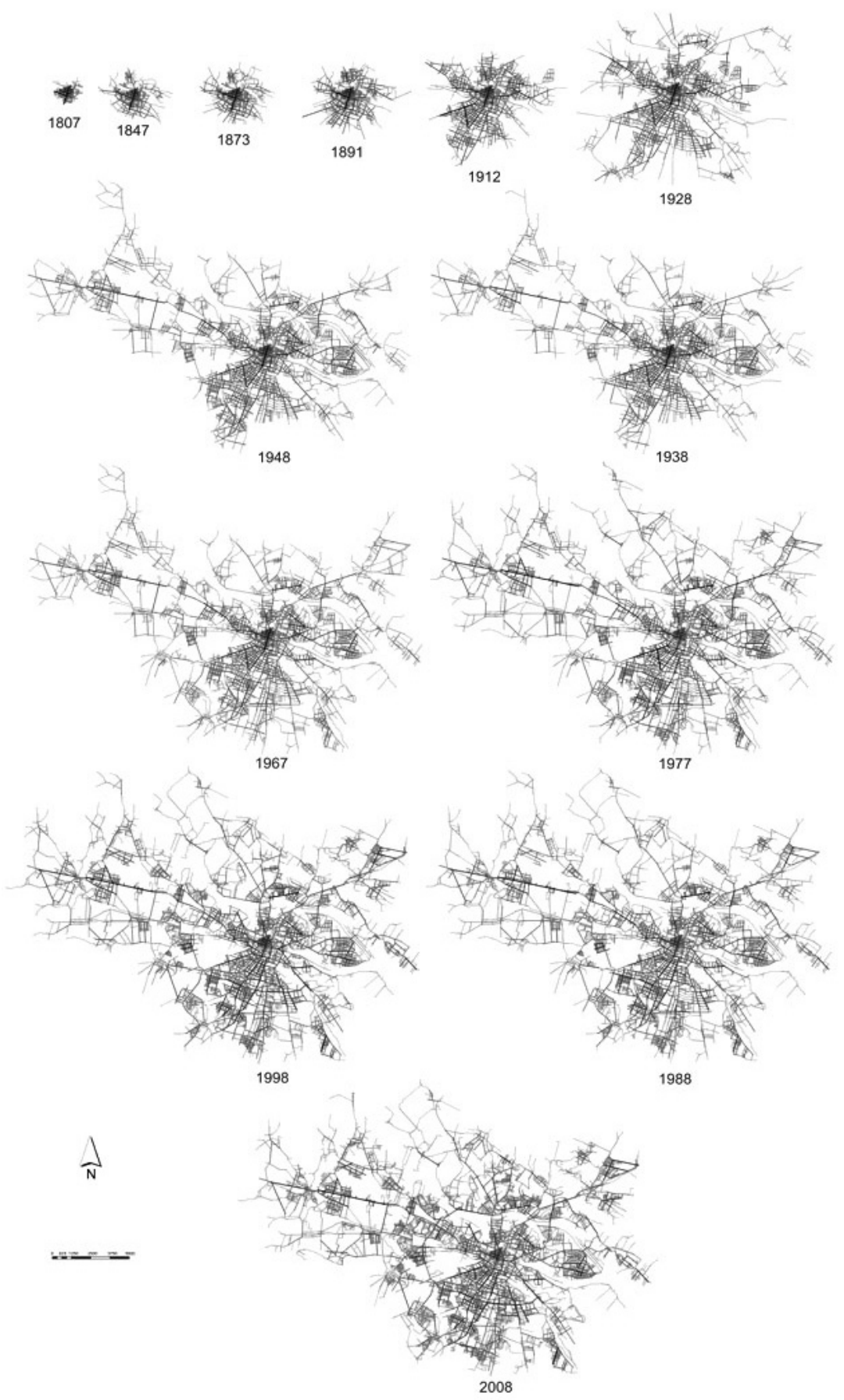

Figure 11. Global choice core of axial maps of Wrocław urban network in different periods Source: author. 


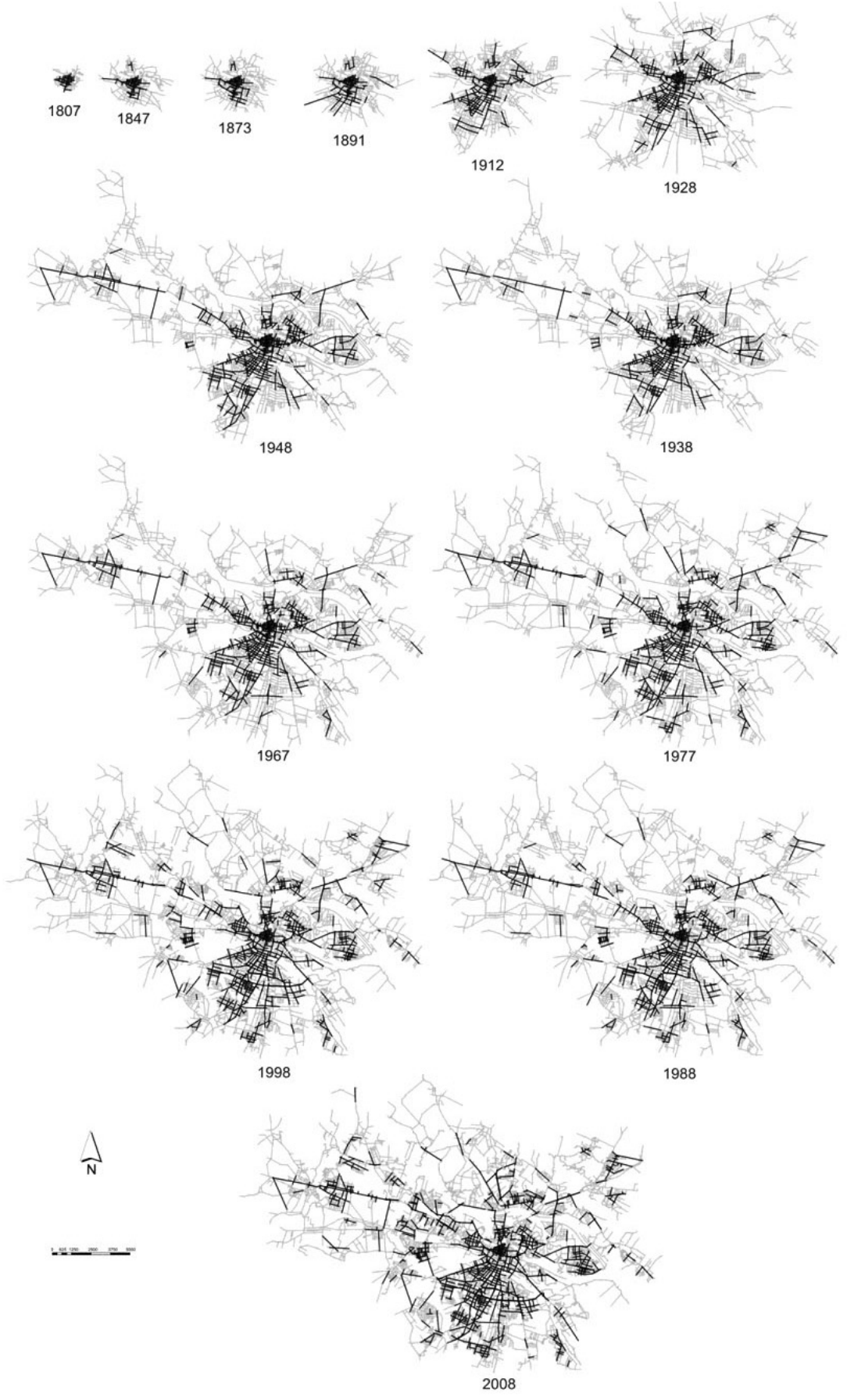

Figure 12. Local integration core of axial maps of Wrocław urban network in different periods

Source: author. 
directions with the peripheral lines or rims (ring road) to provide evidence of a shift in importance from the old city towards the newer part; and prefigures the future trends.

The global choice core of Wrocław was represented by the shortest topological routes within the urban network that connects the historical city centre with edge of Wrockaw, at the same time; it connects the main centre with the sub centres. This core was described as a global betweenness centrality of Wrocław urban network that was shaped a pattern of global accessibility. Figure 11 shows how the global choice core within the urban network of Wrocław through the different study periods from 1804 to 2008.

The local integration core of Wrocław was described as a local closeness centrality of Wrockaw urban network that was shaped a pattern of local accessibility. This core was represented by the most important local parts within the whole urban network to generate the sub centres of the local urban areas. In 1804, the local integration core of Wrocław was created as a one part within the city centre, as it is shown in Figure 12. Through the time this core was started to expand with the urban growth of the urban network to generate new parts, to shift to another parts or to connect with another parts that were as small town centres.

\section{CONCLUSIONS}

In this paper, the spatial analysis according to space syntax methodology showed the morphological transformation of the urban network of Wroclaw city caused by the rapid development and urban growth impacts. The syntactic parameters were confirmed that the historical city centre of Wroclaw kept its centrality attributes so strongly despite the metropolis growth and emerging new centralities. In other words, this centre doesn't reflect the typological or physical background of the city only but it is a social, cultural and educational foreground for a long time.

Within the urban network of Wrocław, there are two kinds of centrality, the local centrality and global centrality. The local centrality was shaped by the structures of main centre and sub centres while the global centrality was shaped by the structure of roads that connect the edge of the city with the main centre and connect the main centre and sub centres between them. The results of Wrockaw urban network analysis confirm the global centrality structure is a constant structure within the whole system of urban network, while the local centrality structures are dynamic. These local structures can be shift, shrinkage, diversify or expand at the same time can be create hierarchy of local centre or sub centre, are depended on the topological, geometrical and syntactical properties of urban network. From these two kinds of centrality emerged two kinds of accessibility, the local accessibility and global accessibility. These two kinds of accessibility had impacts on the concentration and distribution of the economic agglomeration, labour market and property values.

In this paper, the spatial analysis of Wrocław urban network had taken within the administration boundary of Wrocław's municipality, from this perspective there are questions have been emerged, what are the results would be if the structure of 
Wrocław urban network studied within different radii without taken in the account the administration boundary? And, are the cores will take the same results within the urban network or will take another shape? From global verses local centrality point of view, can be determine the structure of urban network of Wrocław metropolitan area? And which is the small settlement around Wroclaw would be sub centres within the metropolitan region. The findings of these questions will create some amount of incentive for future researcher to improve the spatial analysis of Wrocław urban network due to their morphological transformation urban pattern.

\section{REFERENCES}

ARAW (2009), Driven by Knowledge, Wrocław Agglomeration Development Agency, < http://araw.pl/artykuly/6/Download/> (5, September 2009).

Figueiredo, L. (2005), Mindwalk: a Java based software for spatial analysis, Proceedings of the 5th Space Syntax International Symposium, Delft University of Technology, Delft.

Hillier, B. and Hanson, J. (1984), The social logic of space, Cambridge University Press, Cambridge.

Hillier, B., Hanson, J. and Peponis, J. (1987), The syntactic analysis of settlements, Architecture and Comportment/Architecture and Behavior, 3, 3, 217-231.

Hillier, B., Penn, A., Hanson, J., Grajewski, T. and Xu, J. (1993), Natural movement: or, configuration and attraction in urban pedestrian movement, Environment and Planning B, 20, 1, 29-66.

Hillier, B. (1996), Space is the machine, A configurational theory of architecture, Cambridge University Press, London.

Jiang, B. C. and Claramunt, C. (1999), A comparison study on space syntax as a computer representation of space, 2nd International Space Syntax Symposium Proceedings, Brasilia, Brazil.

Jiang, B. and Claramunt, C. (2002), Integration of space syntax into GIS: New perspectives for urban morphology, Transactions in GIS, 6, 3, 295-309.

Jiang, B. C. and Klarqvist, C. (2000), An integration of space syntax into GIS for urban planning and design, International Journal of Applied Earth Observations and Geoinformation, 2, 3/4, 161-171.

OECD (2008), Territorial Reviews. Poland, OECD Publishing, Paris.

Peponis, J., Hajinikolaou, E., Livieratos, C. and Fatouros, D. A. (1989), The spatial core of urban culture, Ekistics, 56, 334/335, 43-55.

Statistical Yearbook of Wrocław (2006), Wrocław in figures, official service of the Municipality of Wrocław, <http://www.Wroclaw.pl> (June 6, 2009).

Teklenburg, J. A. F., Timmermans, H. J. P. and Wagenberg, A. (1993), Space syntax: standardized integration measures and some simulations, Environment and Planning B: Planning \& Design, 20, 3, 347-357.

Wang, H. (2009), Space configuration and movement pattern of Chinese traditional settlement, 7th International Space Syntax Symposium Proceedings, Stockholm, Sweden. 
http://rcin.org.pl 